\title{
Wocko, a Neurological Mutant Generated in a Transgenic Mouse Pedigree
}

\author{
E. Bryan Crenshaw III, ${ }^{1,2}$ Allen Ryan, ${ }^{3}$ Stacey R. Dillon, ${ }^{2,4}$ Kristin Kalla, ${ }^{2,4}$ and Michael G. Rosenfeld ${ }^{2,4}$ \\ 'Department of Biology, ${ }^{2} E u k a r y o t i c ~ B i o l o g y ~ P r o g r a m, ~{ }^{3}$ Department of Surgery/Otolaryngology, and 4 Howard Hughes \\ Medical Institute, University of California at San Diego, La Jolla, California 92093-0648
}

\begin{abstract}
Naturally occurring mutations involving the nervous system have provided virtually all of our current understanding of the genetic regulation of neural development (Caviness and Rakic, 1978). The difficulty of isolating the corresponding genes, however, has precluded a molecular analysis of these mutants. Insertional mutagenesis, induced by microinjection of DNA into fertilized ova to produce transgenic animals, provides a molecular tag that marks the site of the mutational event. In this article, we describe a transgenic neurological mutation, designated wocko (Wo), which disrupts the development of the inner ear. These mutant mice display a dominant behavioral phenotype that consists of circling, hyperactivity, and head tossing, reminiscent of the shaker/ waltzer class of mutants, and they display a recessive homozygous sublethal phenotype. Anatomical analyses showed that both structural and neural components of the vestibular system were disrupted, while analyses of mutant fetuses showed that these morphological abnormalities were due to aberrant development. Although low levels of transgene expression were detected using a sensitive PCR assay, several nonmutant pedigrees that contain the same construct also expressed the transgene in the inner ear, suggesting that Jow levels of transgene expression alone were not responsible for the wockophenotype. Because the integrated transgene provides a marker to clone the wocko mutation, the analysis of this mutant will give unique insight into the molecular genetics of inner ear development and into a broad class of neurological mutations that affect the inner ear.
\end{abstract}

Development of the nervous system is controlled ultimately at the level of gene expression. This has been shown directly in the powerful genetic systems of Drosophila and C. elegans, in which many loci that regulate neural development have been characterized and their corresponding genes isolated. However, in mammalian systems, the selection of developmental mutants and isolation of the corresponding genes is a laborious process. Over the last few decades, a limited number of mammalian mutants that affect the development of the nervous system have been observed, and the molecular basis of only a handful of

\footnotetext{
Received Oct. 1, 1990; revised Jan. 9, 1991; accepted Jan. 15, 1991.

We thank Tara Rachinsky, Sen Li, Thecla Bennett, and Drs. Betsy Kiethley and Stuart Leff for their help and critical reading of the manuscript. This work is supported by NIH/NIDCD Grant DCO0139, by the research service of the Veterans Administration, and the Howard Hughes Medical Institute.

Correspondence should be addressed to Michael G. Rosenfeld, School of Medicine, 0648, CMM Room 345, University of California at San Diego, La Jolla, CA 92093-0648.

Copyright (C) 1991 Society for Neuroscience $0270-6474 / 91 / 111524-07 \$ 03.00 / 0$
}

these mutants has been characterized (Mason et al., 1986; Readhead et al., 1987; Balling et al., 1988; Li et al., 1990; Yoshida et al., 1990).

Most known mammalian neurological mutants alter the development and function of the inner ear (Peters, 1990). Over 60 inner ear mutants are categorized in the shaker/waltzer class of mutants, which constitutes approximately one-tenth of the murine mutants isolated to date. Aspects of inner ear morphology that are influenced by a single gene can, with some limitations, be inferred from the effects of single-gene mutations that produce alterations in the labyrinth. For example, the fact that the cochlea and saccule on the one hand, and the utricle and the semicircular canals on the other, are often affected differently by inner ear mutations suggests that the development of these two portions of the labyrinth are differentially regulated. In analyzing a specific mutation, Deol (1963) concluded that diverse inner ear defects in the mutant mouse shaker with syndactylism, $s y / s y$, were caused by an abnormality in the relationship between the epithelium of the otic labyrinth and the surrounding mesenchymal tissue, observed during prenatal development. Although these observations provide interesting insights into the morphological aspects of inner ear development, these naturally occurring mutants provide little insight into the molecular basis of development.

One limitation to the study of naturally occurring inner ear mutations in mammals is the difficulty inherent in locating the site of a mutation, so that genes can be isolated and gene products identified. Even a detailed genetic linkage analysis can only narrow down the site of a mutation to 1 centiMorgan, or approximately $10^{6}$ base pairs (bp). This leaves a large expanse of DNA through which to search for the gene sequence. For this reason, no gene that affects inner ear function or development has yet been characterized at the molecular level.

Iransgenic animals, generated by the insertion of foreign DNA into the genome of a species such as the mouse, are increasingly used to study the developmental effects of identified gene sequences (for review, see Palmiter and Brinster, 1986; Rosenfeld et al., 1988). While most such insertions do not interfere with the host genome, an estimated 7-20\% of insertions (Palmiter and Brinster, 1986; Gridley et al., 1987) disrupt the host genome causing a mutation. Such mutations have the advantage that the site of integration induces and marks the disrupted gene. We have isolated and characterized such a mutation that affects the development of the inner ear.

\section{Materials and Methods}

Plasmid construction and production of transgenic mice. The vasopressin- $v$-src construction consisted of the human vasopressin $5^{\prime}$ flanking 


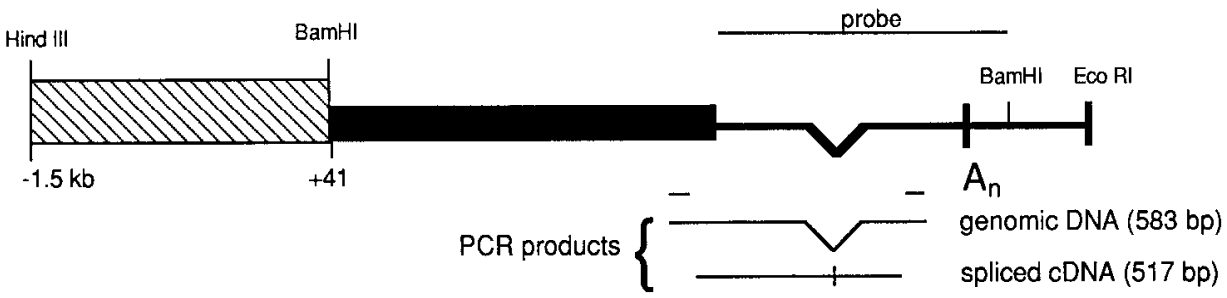

Figure 1. Schematic illustration of the vasopressin-v-src construct. The vasopressin-v-src construct consisted of the human vasopressin $5^{\prime}$ flanking region from $-1.5 \mathrm{~kb}$ to $+41 \mathrm{bp}, \mathrm{a} 1.9-\mathrm{kb}$ segment of the $v$-src gene from the Schmidt-Ruppin A-strain of RSV, and a 1.6-kb segment of the splicing and polyadenylation signals of SV40 early region. The fragment was excised from its vector sequences by restriction with HindIII and EcoRI. regions ligated to the $v$-src gene of Rous sarcoma virus (RSV) and the splicing and polyadenylation signals from simian virus 40 (SV40). The segment containing the human vasopressin promoter region (a generous gift from J. Battey, Naval Hospital, Bethesda, MD) extended from the endogenous HindIII site at -1.5 kilobases $(\mathrm{kb})$ to the HgiAI site at +41 (Sauseville et al., 1985), which was converted to a BamHI site by T4 polymerase exonuclease treatment followed by ligation of a BamHI linker. The $v$-src segment consisted of a 1.9-kb fragment of the SchmidtRuppin A-strain of Rous sarcoma virus (a generous gift of Harold Varmus and Nancy Quintrell, University of California at San Francisco) from the AccI site (converted to a BamHI site with linkers) to the NruI site, which was destroyed after ligation into the construct (DeLorbe et al., 1980; Luciw et al., 1983). The segment containing the SV40 splicing/ polyadenylation signals was derived from a $1.6-\mathrm{kb}$ fragment of the $\mathrm{pSV} 2$ vector (Subramani and Southern, 1983); the BglII site at the $5^{\prime}$ end of the pSV2 splice site was destroyed during construction, and the transgenic fragment ends at the endogenous EcoRI site that was $3^{\prime}$ of the polyadenylation signal. For microinjection, the fragment was excised from its pUC18 vector by HindIII and EcoRI.

Microinjection into fertilized (C57BL/6J $\times \mathrm{DBA} / 2 \mathrm{~J}) \mathrm{F} 1 \mathrm{eggs}$ and transfer to pseudopregnant females were done as previously described (Hogan et al., 1986; Crenshaw et al., 1987). Transgenic mice were identified by dot blot analysis of DNA extracted from a segment of the tail as described by Palmiter et al. (1982). A specific DNA probe was the BamHI fragment of the pSV2-CAT-2 vector (specific for the splicing and polyadenylation signals from SV40), the whole $\mathrm{pSV} 2 / \mathrm{L}$ plasmid (de Wet et al., 1987; contains both the luciferase cDNA as well as the splicing and polyadenylation signals from SV40), or the HindIII to BamHI fragment from the transgene encompassing the human vasopressin promoter. Fragments were labeled to high specific activity by the random priming method (Feinberg and Vogelstein, 1983).

Histological techniques. For morphological assessment of the inner ear and brain, adult and newborn animals were deeply anesthetized and perfused with mixed aldehydes (1\% paraformaldehyde and $1 \%$ glutaraldehyde in phosphate buffer, $\mathrm{pH}$ 7.2). For light microscopy, inner ears were decalcified in $10 \%$ EDTA for 1 week, postfixed in $2 \% \mathrm{OsO}_{4}$, and embedded in Spurr's resin. Semithin $(2.0-\mu \mathrm{m})$ sections were cut on glass knives and stained with toluidine blue. Fixed brains were sunk in $30 \%$ sucrose and sectioned at $20 \mu \mathrm{m}$. Sections were stained with cresyl violet for light microscopy.

For in situ mRNA hybridization, whole fetuses [embryonic day 12 (E12) and E14] or fetal heads (E15, E16, and E18) were fixed by immersion in $4 \%$ paraformaldehyde with $0.25 \%$ glutaraldehyde $(\mathrm{pH}, 9.5)$, sunk overnight in $4 \%$ paraformaldehyde with $30 \%$ sucrose, and frozen in a 50/50 mixture of OCT and Aquamount. Frozen sections were cut at $20 \mu \mathrm{m}$, mounted on poly-L-lysine coated slides, and treated with $1 \%$ Triton X-100. They were hybridized with riboprobes synthesized from regions of the SV40 virus found in the transgene that encompassed the splicing and polyadenylation signals. For further details of the hybridization histochemistry, see Simmons et al. (1989).

Polymerase chain reaction. Timed matings were established with the day of vaginal plug designated as day 1 . In adults, the temporal bone was divided into vestibular and cochlear halves, and RNA extracted by the acid-guanidinium-phenol-chloroform method (Chomczynski and Sacchi, 1987). In fetuses, a segment of temporal bone containing the inner ear was dissected from the fetal material, and RNA was isolated as above. cDNA was made using the Riboclone cDNA Synthesis System (Promega) as per manufacturer's instructions except that the manufacturer's reverse transcriptase was substituted by enzyme from Seikagaku, Inc. PCR analysis was carried out using the GeneAmp kit (Perkin Elmer Cetus). The sense-strand oligonucleotide consisted of a segment in the $3^{\prime}$ end of the $v$-src gene ( $5^{\prime}$-AAGGCAAGGCTTGACCGACAA- $\left.3^{\prime}\right)$. The antisense strand is complementary to a segment of the SV40 virus (5'GCAGACACTCTATGCCTGTGTGGA-3'). cDNA $(2.5 \mu \mathrm{l})$ was amplified for 30 cycles $\left(1 \mathrm{~min}\right.$ at $94^{\circ} \mathrm{C}, 2 \mathrm{~min}$ at $56^{\circ} \mathrm{C}$, and $3 \mathrm{~min}$ at $72^{\circ} \mathrm{C}$ ) in a $50-\mu 1$ volume, and $10 \mu \mathrm{l}$ was analyzed by electrophoresis on a $1.2 \%$ agarose gel.

\section{Results}

\section{Establishment of the developmental mutant}

Transgenic mice were generated by microinjection of a chimeric gene consisting of the $5^{\prime}$ flanking region of the human vasopressin gene fused to the $v$-src gene of RSV (Fig. 1), with the splicing/polyadenylation signals derived from SV 40 . Fourteen pedigrees of transgenic mice were generated by microinjection of the transgene into the pronucleus of fertilized mouse oocytes and transfer into pseudopregnant females. While most of these pedigrees exhibited normal behavior, one of the 14 lines showed a behavioral phenotype, consisting of bidirectional circling, hyperactivity, and head tossing in a vertical planc (line VS-41p). Even at the earliest stage examined ( $2 \mathrm{~d}$ postparturition), the mutant pups could be distinguished from their normal littermates because they had difficulty righting themselves when inverted. Although naturally occurring shaker/waltzer mutants with equilibrium problems are often deaf (Deol, 1980; Steel et al., 1983), the mature transgenic animals (3-6 months) were startled by sudden sounds (Preyer's reflex). Even though some females have difficulty caring for their litters, both sexes of this transgenic line are fertile, and their lifespan is apparently normal.

The corneas of some animals, especially males, are opaque, and morphological analyses of fetal mice show that this defect is probably due to early eyelid opening. Gross morphological analyses of internal organs revealed no defects, and histological analyses of kidney and brain also showed no other discernible defects.

\section{Genetic analyses show a dominant homozygous sublethal phenotype}

The nature of the transgenic integration event in the mutant strain was assessed by genetics and Southern blot analysis. The founder mouse (female 41) transmitted the transgene in a Mendelian fashion to progeny of both sexes (four of eight progeny were transgenic). Mendelian transmission was maintained in the progeny of the founder animal, indicating that this pedigree contained a single integration event on an autosomal chromosome. The waltzing phenotype in the wocko strain cosegregates with the transgene in $>220$ animals that have been analyzed to date and has never been detected in a sibling that was not transgenic. The penetrance of the phenotype was complete. Southern blot analyses indicated that a single copy of the trans- 
a

Figure 2. Schematic illustration of the labyrinth in normal and wocko adult mice. $a$, The membranous labyrinth of a normal mouse. This schematic illustrates the structures that compose the two functional divisions of the inner ear: the vestibular system and the cochlea $(c)$. Here, we depict the membranous portion of the inner ear, which is encased in the bony labyrinth, a cavern within the temporal bone. The vestibular system is arranged into three compartments: the utricle $(u$; located at the base of the semicircular canals), the saccule (s), and the semicircular canals. $b$, The wocko labyrinth. The utricle and semicircular canals are collapsed in the inner ear, while the saccule and cochlea are spared.

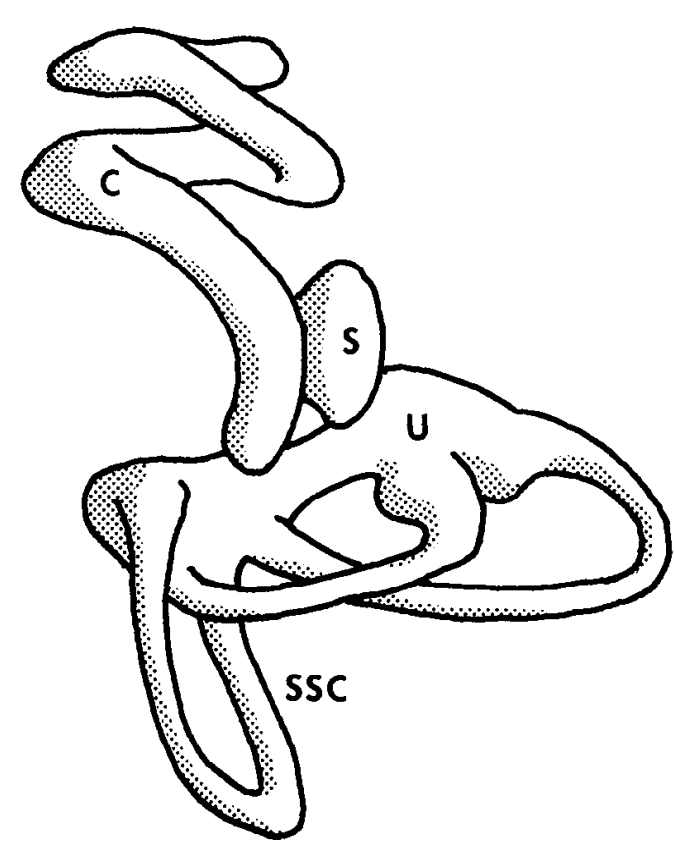

b

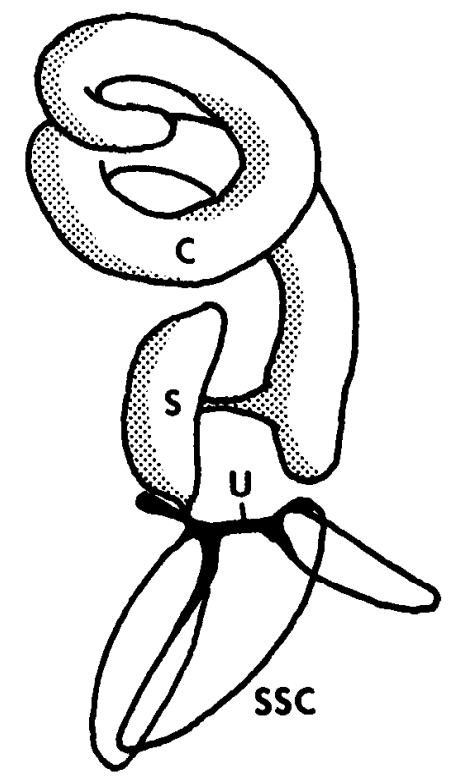

gene was integrated into the genome of this pedigree (data not shown).

To examine the homozygous state of the wocko mutants, the progeny from intercross $(\mathrm{Wo} /+\times \mathrm{Wo} /+)$ matings that displayed the circling phenotype were tested for the possibility of being homozygous $(\mathrm{Wo} / \mathrm{Wo}$ ) by mating to normal (C57BL/6 J $\times \mathrm{DBA} / 2 \mathrm{~J}$ )F 1 mice (outcross). If homozygotes were completely viable, one would expect a heterozygote : homozygote ratio of 2:1. Of $19 \mathrm{Wo} /+$ ? animals from such intercross matings, only one animal is homozygous, as demonstrated by the fact that it transmitted the wocko phenotype to all $(n=11)$ of its progeny. The 18:1 ratio of homozygotes to heterozygotes is significantly different from the expected $2: 1$ value $(p=0.04$, Fisher's exact test). These data demonstrate that the wocko mutation is homozygous sublethal, indicating that the gene interrupted by the transgene insertion is important for the survival of the animal.

\section{Characterization of the adult inner ear}

Because the circling/waltzing behavior is typically induced by disruptions of the inner ear, we undertook an anatomical examination of the mutants. Figure $2 a$ schematically depicts the anatomy of the normal inner ear, which is composed of two major functional units: the vestibular system, responsible for determining the position and movement of the head in space, and the cochlea, responsible for translating sounds into neural signals. The vestibular system is subdivided into three anatomically and functionally distinct compartments: the utricle and saccule, which sense primarily the position of the head in space, and the semicircular canals, which sense primarily motion (for review, see Precht, 1979). Figure 2, $a$ and $b$, shows schematics of the labyrinth compiled from serial sections of adult inner ears from normal and wocko mice. Gross morphological changes were observed in the adult (3-5 month) wocko vestibular inner ear, which was characterized by the collapse of the utricle and all three semicircular canals. The cochlea and saccule did not collapse, and their gross morphology appeared macroscopically normal. More detailed histopathological assessment of the vestibular labyrinth revealed that the lumens of the utricle and the semicircular canals were reduced to a narrow space and that the sensory epithelia of these structures had degenerated, leaving only an occasional remnant (Fig. 3a,b). The vestibular ganglion appeared normal, and nerve fibers entered the vestibule, where they projected in a disorganized fashion (Fig. $3 a, b$ ). The sensory neuroepithelium of the saccule (macula) was present in the mutant, but showed a reduced population of both sensory and supporting cells. In many mutants, the otoconia of the saccular macula were giant and spherical in form (Fig. $3 c, d$ ).

Consistent with the fact that the animals are not deaf, the cochlea of the mutant was relatively normal in appearance. However, the apical turn of all mutants displayed loss of spiral ganglion cells and their associated nerve fibers, which in some cases was extensive (Fig. 4). The sensory cells in the apex of the cochlea also showed losses, but they were usually less extensive than those of the ganglion cells. Also, throughout the cochlea, the spiral limbus was reduced in size relative to the normal mouse, and the interdental cells at the apical surface of the limbus were highly disorganized (Fig. 4).

Although the vestibular portion of the inner ear was highly dysmorphic, the accessory vestibular nuclei of the cerebellum in the wocko mutants were present and apparently normal in these animals. The cerebellar flocculus and paraflocculus were reduced in size, consistent with their normal anatomical location within the arcs of the semicircular canals (data not shown).

\section{Analysis of the ontogeny of the mutant inner ear}

To confirm that the dysmorphology was due to aberrant development, we examined the ontogeny of the inner ears of wocko mice. Fetuses at E12, E14, E15, E16, and E18 were examined by histological staining; morphological abnormalities were first observed in the wocko inner ear at E16. These abnormalities were evidenced by constriction of the lumen of the semicircular canals and absence of otoconia on the utricular macula (Fig. 5, 

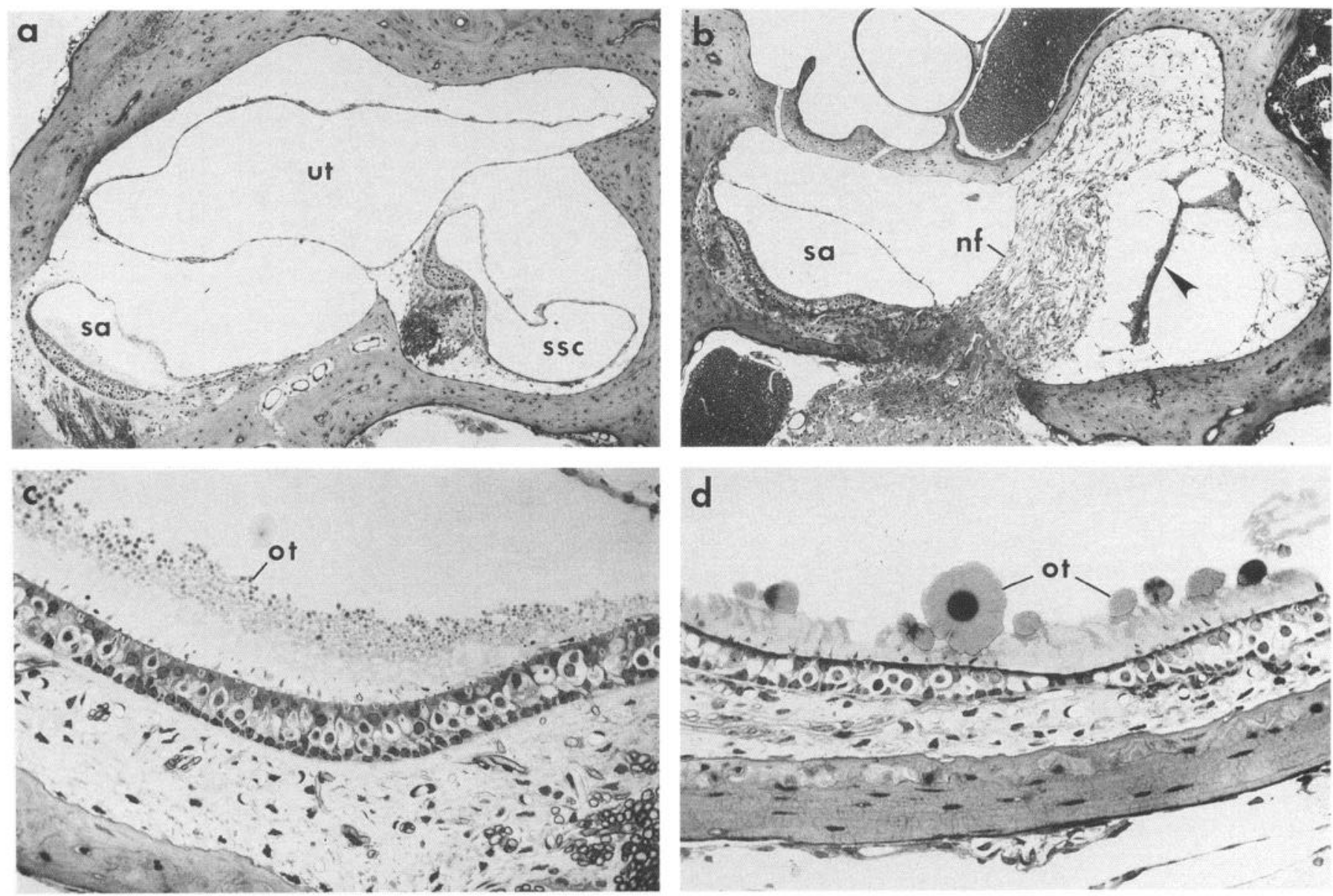

Figure 3. Anatomical analyses of the vestibular system of wocko mice: the vestibular inner ear of the normal and wocko mouse. A section through the vestibule of the normal mouse $(a)$ shows both the saccule $(s a)$ and utricle $(u t)$ and the semicircular canal organs (ssc), with vestibular nerve fibers projecting to the sensory epithelia (higher magnification in $c$ ). A comparable section through the wocko vestibule $(b)$ shows a recognizable saccular macula, but complete collapse of the utricle and semicircular canals (arrowhead) and absence of their sensory epithelia. Nerve fibers ( $n f$ ) project from the vestibular ganglion into the vestibule in a disorganized manner. In comparison to the saccular macula of the normal mouse (c), that of wocko $(d)$ shows malformed, giant otoconia $(o t)$, as well as reduced hair cell and supporting cell populations.

top row). At birth, the mutant inner ear displayed constricted semicircular canals (Fig. 5, middle row), with arcs of smaller than normal size. The saccular and utricular maculae were present at birth, but otoconia were present only on the saccular macula. The sensory epithelia of the three semicircular canals were present. At birth, no loss of spiral ganglion cells was apparent in the apex. However, the spiral limbus was less well organized than in the normal newborn mouse (data not shown).
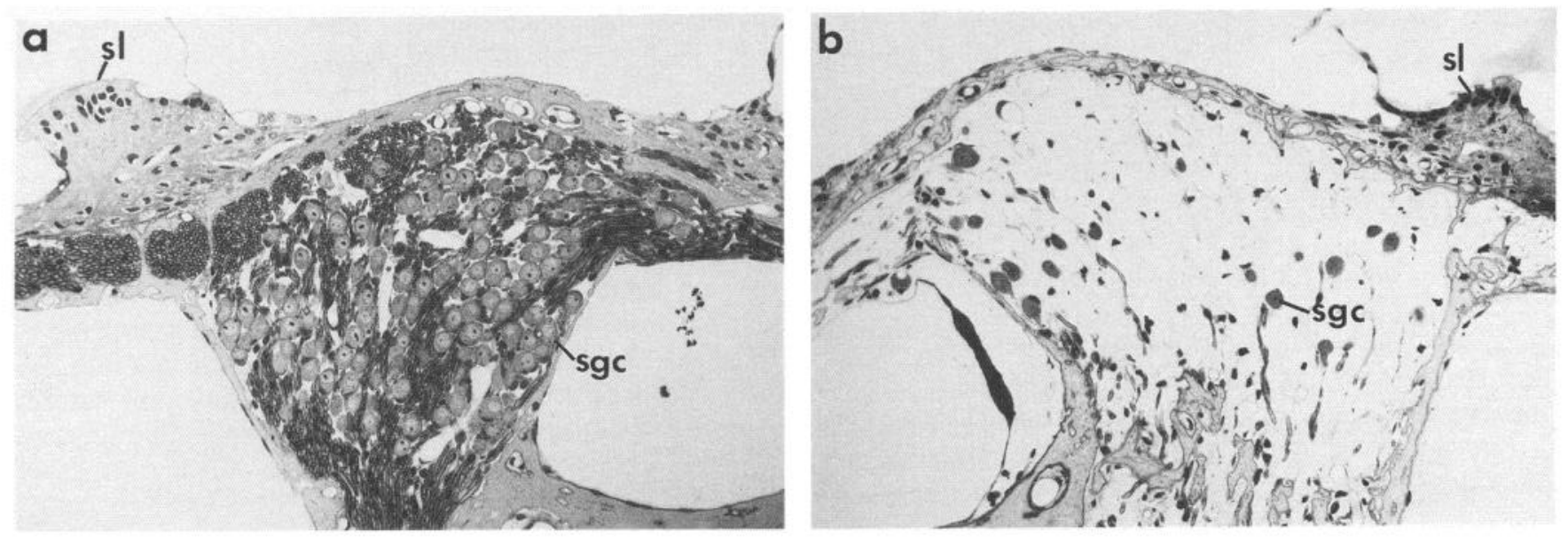

Figure 4. Anatomical analyses of the cochlea of wocko mice: the apical modiolus of the normal $(a)$ and wocko $(b)$ mouse. This mutant exhibited nearly complete loss of spiral ganglion cells $(s g c)$ in the apical third of the cochlea. Also, the spiral limbus $(s l)$ is disorganized and reduced in size. 

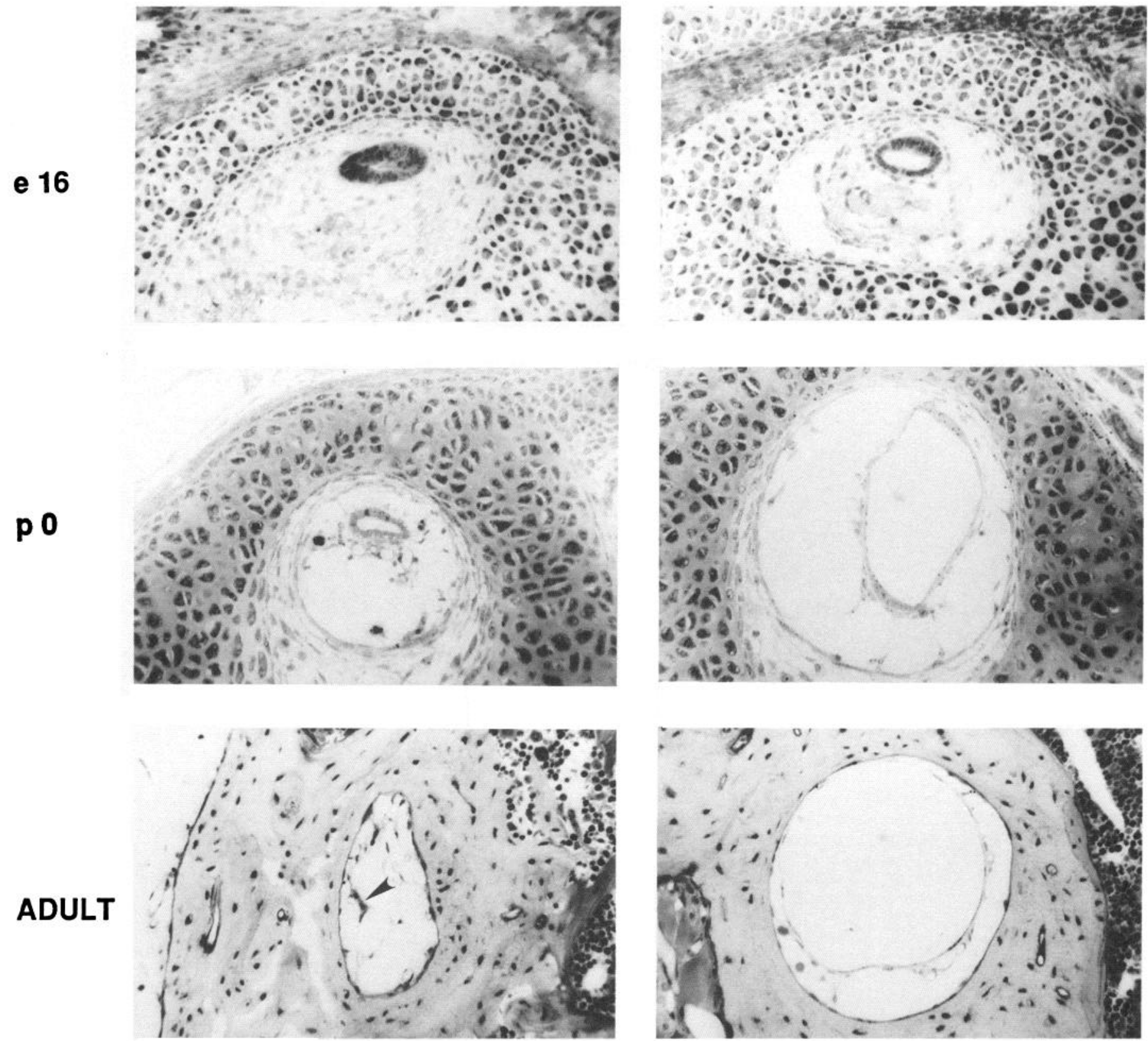

\section{WOCKO}

NORMAL

Figure 5. The ontogeny of the wocko phenotype. The right column shows sections from the normal mouse; the left column shows sections from the wocko mouse. The upper row illustrates the initial defects observed in the semicircular canals of the E16 fetus, which consist of a restricted lumen. The middle row illustrates semicircular canal defects at postnatal day 1 ; the bottom row shows the adult animal characterized by collapse of the endolymphatic space in the semicircular canals (arrowhead).

\section{Analysis of transgene expression in the mutant}

To determine whether the transgene was expressed during the ontogeny of the inner ear, we have examined wocko mutants by in situ hybridization histochemistry and PCR. In parasagittal sections throughout the head of fetal mutant mice that were hybridized with ${ }^{35} \mathrm{~S}$-labeled antisense RNA probe, no transgene expression was detected in any structure within the fetal head (data not shown). Using the highly sensitive PCR method, very low levels of expression were detected in the cochlea and vestibule of adult wocko animals and in fetal wocko inner ears. However, transgene expression was also detected in several other nonmutant pedigrees containing the same construct (Fig. 6a,b), suggesting that expression of the transgene alone is not capable of inducing the waltzing phenotype. A semiquantitative PCR analysis, in which a dilution series of inner ear CDNA was amplified and quantitated by hybridization with a labeled probe, showed that transgene expression levels in the mutant pedigree 
a Adult

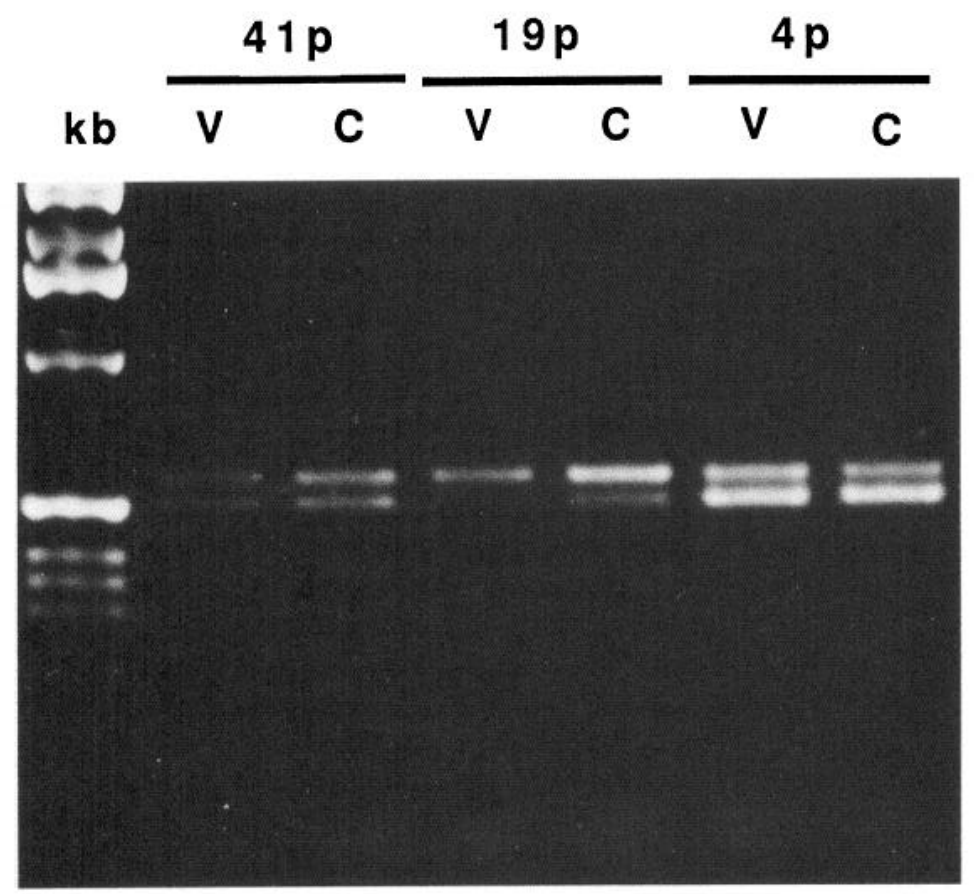

b Fetal

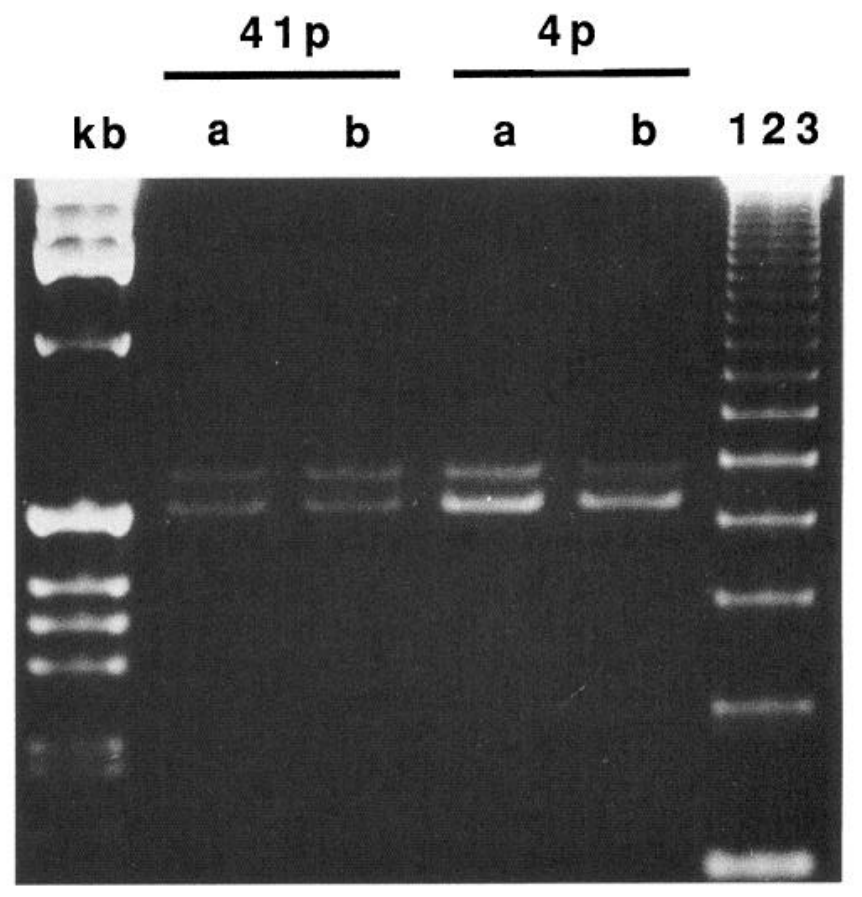

Figure 6. PCR analysis of transgene expression. $a$, PCR analysis of cDNA from adult inner ears demonstrates that low levels of transgene expression can be detected in the vestibule $(V)$ and cochlea $(C)$ of adult mutant wocko mice $(41 p)$ and from mice of other nonmutant pedigrees containing the same transgenic construct $(19 p, 4 p)$. PCR amplification generates $t w o$ bands of $583 \mathrm{bp}$ and $517 \mathrm{bp}$. The upper band represents amplification of small amounts of residual genomic DNA from the transgene that remains after RNA isolation and is amplified in the absence of transgene expression. The lower band represents amplification of the cDNA in which the 66-bp SV40 small splice site has been removed, and is diagnostic for transgene expression. A $1-k b$ ladder (Bethesda Research Laboratory) provides size standards. $b$, PCR analysis of cDNA from fetal (E18) inner ears indicates that transgene expression can be detected in mutant and nonmutant pedigrees. Fetal inner ears from two individuals $(a, b)$ from the wocko $(41 p)$ and from a phenotypically normal transgenic line $(4 p)$ are shown. Size standards are $1-k b$ and $123-b p$ ladders.

(41p) and a nonmutant pedigree (4p) are roughly equivalent (data not shown). Because the levels of expression in the mutant and nonmutant lines are roughly equivalent, it is unlikely that the wocko phenotype is the result of higher levels of transgene expression in the single mutant wocko pedigree than in the 13 nonmutant pedigrees containing the same transgene. However, it is possible that transgene expression occurs in a different population of inner ear cells in the wocko pedigree than in the normal pedigrees.

\section{Discussion}

The analysis of the molecular basis of mammalian neural development will require the isolation of genes that regulate temporal and spatial changes in gene expression and morphology. The isolation of these developmental genes in mice will be greatly facilitated by insertional mutants produced during the generation of transgenic mice. This article characterizes the first insertional mutation in transgenic mice that affects the development and the function of the inner ear.

Wocko resembles several naturally occurring inner ear mutations of the shaker/waltzer family. This heterogeneous family of mutations involves at least 30 genes that are distributed among most mouse chromosomes (Deol, 1980; Steel et al., 1983; Peters, 1990) and shows a wide range of abnormalities of the labyrinth. These abnormalities are often restricted to one or more components of the labyrinth. In terms of the structures primarily affected by the mutation, wocko most closely resembles dancer, in which collapse of the utricle and two semicircular canals is observed (Deol and Lane, 1966). However, the embryonic development of dancer is characterized by loss of vestibular nerve branches, which has not been observed in prenatal wocko. Therefore, it is likely that the mechanisms by which abnormalities arise in dancer are quite distinct from those operating in wocko.

Grüneberg (1956) has classified shaker/waltzer mutants into morphogenetic mutations, in which labyrinthine structures develop abnormally, and degenerative mutants, in which the inner ear develops normally but then degenerates after birth. Wocko exhibits both morphogenetic and degenerative components, though the latter are certainly more extensive. The mutant rotating also displays both morphogenetic and degenerative components, developing with severe constriction of the semicircular canals and then showing later degeneration of the saccular macula (Deol and Dickie, 1967). A classification scheme was developed more recently by Steel and Bock (1985) that further divides the degenerative mutants into neuroepithelial degeneration and cochleosaccular degeneration. Wocko does not fit neatly into either of these classifications, though it is closer to the neuroepithelial degeneration category.

Although the dominant nature of this mutation may have resulted from the inappropriate expression of the transgene, several observations dispute this possibility. Only 1 of 14 pedigrees that contain the transgene expresses the wocko phenotype, suggesting that a unique integration event occurred in the wocko 
pedigree. Because we find that vasopressin/v-src expression is found in several nonmutant pedigrees, it is unlikely that this unique integration event resulted in a pattern of ectopic transgene expression in mutant inner ears that is responsible for the observed phenotype. However, we cannot completely rule out this possibility. Furthermore, at least one other pedigree expresses the transgene at levels comparable to the mutant pedigree; therefore, it is unlikely that the level of transgene expression can explain the difference between the mutant and nonmutant strains. Finally, there are $>15$ autosomal dominant mutations that produce a waltzing phenotype and morphogenetic abnormalities similar to, but not identical to, wocko. Interestingly, most of the dominant shaker/waltzer mutants are homozygous lethal mutations (Peters, 1990), similar to wocko. The homozygous sublethal nature of the wocko mutation indicates that the integration event has interrupted a gene that is important for the normal development of the embryo. In toto, these arguments provide a strong basis for the interpretation that the wocko integration event induces a mutational consequence in this pedigree.

Although inner ear mutants represent a large percentage of the known naturally occurring mouse mutations, virtually nothing is known about their molecular basis. The transgene provides a molecular "tag" for the cloning of the wocko mutation and its normal counterpart. Therefore, this mutant will provide for the first time insight into the molecular genetics of inner ear development and mutations that induce circling behavior and deafness.

\section{References}

Balling R, Deutsch U, Gruss P (1988) undulated, a mutation affecting the development of the mouse skeleton, has a point mutation in the paired box of Pax 1. Cell 55:531-535.

Caviness VS, Rakic P (1978) Mechanisms of cortical development: a view from mutations in mice. Annu Rev Neurosci 1:297-326.

Chomczynski P, Sacchi N (1987) Single-step method of RNA isolation by acid guanidinium thiocyanate-phenol-chloroform extraction. Anal Biochem 162:156-159.

Crenshaw EB III, Russo AF, Swanson LW, Rosenfeld MG (1987) Neuron-specific alternative RNA processing in transgenic mice expressing a metallothionein-calcitonin fusion gene. Cell 49:389-398.

DeLorbe WJ, Luciw PA, Goodman HM, Varmus HE, Bishop JM (1980) Molecular cloning and characterization of avian sarcoma virus circular DNA molecules. J Virol 36:50-61.

Deol MS (1980) Genetic malformations of the inner ear in the mouse and man. In: Morphogenesis and malformation of the ear (Gorlin RJ, ed). New York: Liss.

Deol MS (1963) The development of the inner ear in mice homozygous for shaker-with-syndactylism. J Embryol Exp Morph 11:493-512.

Deol MS, Dickie MM (1967) Rotating, a new gene affecting behavior and the inner ear in the mouse. J Hered 58:69-72.
Deol MS, Lane PW (1966) A new gene affecting the morphogenesis of the vestibular part of the inner ear in the mouse. J Embryol Exp Morphol 16:543-558.

de Wet JR, Wood KV, DeLuca M, Helinski DR, Subramani S (1987) Firefly luciferase gene: structure and expression in mammalian cells. Mol Cell Biol 7:725-737.

Feinberg AP, Vogelstein B (1983) A technique for radiolabeling DNA restriction endonuclease fragments to high specific activity. Anal Biochem 132:6-13.

Gridley T, Soriano P, Jaenisch R (1987) Insertional mutagenesis in mice. Trends Genet 3:162-166.

Grüneberg $H$ (1956) Hereditary lesions of the labyrinth in the mouse. Br Med Bull 12:153-157.

Hogan B, Costantini F, Lacy E (1986) Manipulating the mouse embryo. A laboratory manual. Cold Spring Harbor, NY: Cold Spring Harbor Laboratory.

Li S, Crenshaw EB III, Rawson E, Simmons DM, Swanson LW, Rosenfeld MG (1990) Dwarf locus mutants which lack three cell types result from mutations in the POU-domain gene, Pit-1. Nature 347: 528-533.

Luciw PA, Bishop JM, Varmus HE, Capecchi MR (1983) Location and function of retroviral and SV40 sequences that enhance biochemical transformation after microinjection of DNA. Cell 33:705716.

Mason AJ, Hayflick JS, Zoeller RT, Young WS III, Phillips HS, Nikolics K, Seeburg PH (1986) A deletion truncating the gonadotropin-releasing hormonc gene is responsiblc for hypogonadism in the hpg mouse. Science 234:1366-1371.

Palmiter RD, Brinster RL (1986) Germ-line transformation of mice. Annu Rev Genet 20:465-500.

Palmiter RD, Chen HY, Brinster RL (1982) Differential regulation of metallothionein-thymidine kinase fusion genes in transgenic mice and their offspring. Cell 29:701-710.

Peters J (1990) Gene list. Mouse Genome 86:24-87.

Precht W (1979) Vestibular mechanisms. Annu Rev Neurosci 2:265289.

Readhead C, Popko B, Takahashi N, Shine HD, Saavedra RA, Sidman RL, Hood L (1987) Expression of a myelin basic protein gene in transgenic shiverer mice: correction of the dysmyelinating phenotype. Cell 48:703-712.

Rosenfeld MG, Crenshaw EB III, Lira SA, Swanson L, Borrelli E, Heyman R, Evans RM (1988) Transgenic mice: applications to the study of the nervous system. Annu Rev Genet 11:353-372.

Sauseville E, Carney D, Battey J (1985) The human vasopressin gene is linked to the oxytocin gene and is selectively expressed in a cultured lung cancer cell line. J Biol Chem 260:10236-10241.

Simmons DM, Arriza JL, Swanson LW (1989) Complete protocol for in situ hybridization in brain and other tissues with radiolabeled single-stranded RNA probes. J Histotechnol 12:169-181.

Steel KP, Bock GR (1985) Genetic factors affecting hearing development. Acta Otolaryngol [Suppl] (Stockh) 421:48-56.

Steel KP, Niaussat MM, Bock GR (1983) The genetics of hearing. In: The auditory psychobiology of the mouse (Willott JF, ed). Springfield, IL: Thomas.

Subramani S, Southern PJ (1983) Analysis of gene expression using simian virus 40 vectors. Anal Biochem 135:1-15.

Yoshida H, Hayashi S-I, Kunisada T, Ogawa M, Nishikawa S, Okamura H, Sudo T, Shultz LD, Nishikawa S (1990) The murine mutation osteopetrosis is in the coding region of the macrophage colony stimulating factor gene. Nature 345:442-444. 